\title{
Elevational adaptation and plasticity in seedling phenology of temperate deciduous tree species
}

\author{
Yann Vitasse • Günter Hoch • Christophe F. Randin • \\ Armando Lenz • Chris Kollas · J. F. Scheepens • \\ Christian Körner
}

Received: 2 March 2012 / Accepted: 18 December 2012/Published online: 11 January 2013

(C) Springer-Verlag Berlin Heidelberg 2013

\begin{abstract}
Phenological events, such as the initiation and the end of seasonal growth, are thought to be under strong evolutionary control because of their influence on tree fitness. Although numerous studies highlighted genetic differentiation in phenology among populations from contrasting climates, it remains unclear whether local adaptation could restrict phenological plasticity in response to current warming. Seedling populations of seven deciduous tree species from high and low elevations in the Swiss Alps were investigated in eight common gardens located along two elevational gradients from 400 to $1,700 \mathrm{~m}$. We addressed the following questions: are there genetic differentiations in phenology between populations from low and high elevations, and are populations from the upper elevational limit of a species' distribution able to respond to increasing temperature to the same extent as low-elevation populations? Genetic variation of leaf unfolding date between seedlings from low and high populations was detected in six out of seven tree species. Except for beech, populations from high elevations tended to flush later than populations from low elevations, emphasizing that phenology is likely to be under evolutionary pressure. Furthermore, seedlings from high elevation exhibited lower phenological plasticity to temperature than low-elevation
\end{abstract}

Communicated by Russell Monson.

Electronic supplementary material The online version of this article (doi:10.1007/s00442-012-2580-9) contains supplementary material, which is available to authorized users.

Y. Vitasse $(\bowtie) \cdot$ G. Hoch · C. F. Randin · A. Lenz ·

C. Kollas · J. F. Scheepens · C. Körner

Institute of Botany, University of Basel, 4056 Basel, Switzerland

e-mail: yann.vitasse@unibas.ch provenances. This difference in phenological plasticity may reflect the opposing selective forces involved (i.e. a trade-off between maximizing growing season length and avoiding frost damages). Nevertheless, environmental effects were much stronger than genetic effects, suggesting a high phenological plasticity to enable tree populations to track ongoing climate change, which includes the risk of tracking unusually warm springs followed by frost.

Keywords Leaf unfolding - Budset - Common garden . Genecology $\cdot$ Elevational gradients

\section{Introduction}

Deciduous tree species in a temperate climate need to adapt their phenology to optimize the timing of growth and reproduction according to local biotic and abiotic factors (Polgar and Primack 2011). Genetic diversity within and among populations and phenotypic plasticity of phenological key events, such as the emergence of leaves or flowers, play crucial roles in adaptation, and thus in species survival and their competitive abilities in the context of the rapid ongoing climate change (Savolainen et al. 2007). In fact, tree phenology fulfills the three criteria required to be considered as adaptive, that is, being able to evolve in response to selective pressures. First, there is a high phenological variation within populations (e.g. Baliuckas et al. 2005; Alberto et al. 2011), second, phenological traits show a high level of heritability (e.g. Billington and Pelham 1991; Howe et al. 2000), and third, phenological traits are tightly related to individual performance/fitness through biotic (Tikkanen and Julkunen-Tiitto 2003; van Asch and Visser 2007; Wesolowski and Rowinski 2008) and abiotic (Augspurger 2008; Chuine 2010) interactions. Temperature 
is assumed to be the main abiotic selective driver leading to clinal variation of diverse adaptive traits along elevational gradients (Oleksyn et al. 1998; Premoli et al. 2007; Bresson et al. 2011), whereas in semi-arid regions, moisture availability can exert similar selective pressure (Broadhead et al. 2003). Variations of functional phenotypic traits along environmental gradients result from three major components which can be partitioned by conducting analyses of variance (Schlichting 1986). The three sources of variance include phenotypic variance due to genotypes $\left(V_{\mathrm{G}}\right)$, phenotypic variance due to environments $\left(V_{\mathrm{E}}\right)$, and variance due to the interaction of genotypes with the environment $\left(V_{\mathrm{G}} \times V_{\mathrm{E}}\right)$. The two latter components represent the phenotypic plasticity, with $V_{\mathrm{E}}$ considered as the environmental component of the plasticity, and $V_{\mathrm{G}} \times V_{\mathrm{E}}$ as the phenotypic plasticity due to genetic differences among genotypes/provenances. The $V_{\mathrm{G}} \times V_{\mathrm{E}}$ interaction reflects genetic diversity in plasticity and is, thus, assumed to represent the heritable component of phenotypic plasticity (Schlichting 1986; Thompson 1991). So, some genotypes/ provenances may show more and others less phenotypic plasticity along the same environmental gradient.

Over the last century, numerous experiments using common gardens have shown genetic differentiation of tree phenology among populations from different elevational or latitudinal provenances (review in Langlet 1971; Morgenstern 1996; with references therein). While these experiments were mostly established to provide information for forest management, there is now renewed interest to assess the ability of tree populations to cope with ongoing climate change (Aitken et al. 2008; Lindner et al. 2010). One question that remains open is whether tree populations growing in contrasting climates will have the same capability to respond to environmental change such as the ongoing climatic changes (Vitasse et al. 2009b; Doi et al. 2010; Hoffmann and Sgro 2011).

At the upper elevational limit of tree species, cold conditions strongly constrain tree phenology: late frosts in spring are frequent, and bud burst timing must be optimized to minimize the danger of frost damage, while at the same time maximizing the length of the growing season to ensure growth and the production of viable seeds. Tree populations growing at their upper elevational limits may therefore undergo a strong selective abiotic pressure and could be well differentiated from those growing at lower elevations, provided there has been sufficient time for genetic differentiation and sufficient genetic isolation. Leading edge populations are usually smaller and more isolated than populations inhabiting the center of the distribution range, leading to a lower genetic diversity (Willi et al. 2007) and possibly to a weaker phenotypic plasticity to cope with new environmental conditions. On the other hand, these populations could also benefit from gene flow from populations inhabiting warmer areas, which would introduce alleles (pre)-adapted to warmer climate and thus allow leading edge populations to cope with rapid climate warming (Lindner et al. 2010; Kremer et al. 2012). Phenotypic plasticity can be directly enhanced by natural selection in heterogeneous environments (Thompson 1991; Schlichting and Pigliucci 1993), and has been proposed as a catalyst in evolutionary processes for local adaptation (Pigliucci et al. 2006). Yet, although numerous studies have reported genetic differentiation in phenology among tree populations from contrasting climates, only a few studies have addressed whether these populations also diverge in their phenotypic plasticity, including the two components $V_{\mathrm{E}}$ and $V_{\mathrm{E}} \times V_{\mathrm{G}}$ (but see Rehfeldt et al. 2002; Baliuckas and Pliura 2003; Williams et al. 2008; Vitasse et al. 2010). The reason is that most of the studies used only one common garden, and, hence, a single common climate which can be more suitable for some provenances than others. Since both genetic- and environment-related factors affect plant phenotype, results from a single common garden (commonly established at a warm location) can give misleading results and do not allow a proper assessment of the response of the tested populations to environmental changes.

Elevational gradients provide a unique "in situ experiment" for exploring the impact of temperature on tree phenology (Körner 2000). The relative short distance between elevations with markedly different temperatures in mountain terrain enables the analysis of temperature effects on plants at otherwise similar conditions. We used common gardens established at different elevations in two main valleys in the Swiss Alps, including seven tree species widely distributed in Europe, to examine genetic differentiation between low- and high-elevation populations and their plastic responses in leaf unfolding and timing of budset to temperature changes. For each species, seedlings from seeds harvested at low and high elevation within each of the two studied areas were investigated. The objectives of this study were to quantify (1) whether populations of deciduous trees growing at their upper elevational limits in the Swiss Alps are genetically adapted in their phenology to face low temperature conditions; (2) the extent to which leaf phenology is influenced by genetic factors (provenance) and temperature; and (3) to compare phenological plasticity between populations from low and high elevations. We hypothesized that (1) cold temperatures have led to genetic differentiation in leaf phenology between tree populations growing at high and lower elevations, assuming that at high elevation, populations undergo a strong directional selection by freezing temperatures, favouring late flushing individuals; and (2) that populations naturally growing close to their upper elevational limits exhibit a lower phenological plasticity to temperature. 


\section{Materials and methods}

Study species and seed sources

Seven deciduous tree species having a wide distribution range in Europe were selected. Fraxinus excelsior L., mainly distributed at low elevation up to about $1,500 \mathrm{~m}$ in the Swiss Alps; Fagus sylvatica L. and Prunus avium L., occurring from low to mid-elevation up to about 1,700 m; Laburnum alpinum (Mill.) Bercht. \& J. Presl. and Acer pseudoplatanus $\mathrm{L}$., two predominantly mid-montane species found up to about 1,900 m; and Sorbus aria L. and Sorbus aucuparia L. distributed between lower montane level and elevations higher than $1,900 \mathrm{~m}$, in particular S. aucuparia which also occurs at the alpine treeline. The precise elevation limits of these species in the two study areas are provided in Vitasse et al. (2012).

For each species, seeds were collected from June to November 2009, according to their maturation stage, at both high and low elevations in two regions of the Swiss Alps, $200 \mathrm{~km}$ apart: the region around St-Maurice, VS (west) and the region around Haldenstein, GR (east) (see Kollas et al. 2012 for further details). Seeds of L. alpinum were obtained in the western region only because this species does not occur naturally in the eastern region of the Swiss Alps. The western and eastern regions were considered as replicates to test low against high elevational provenances. Within regions and species, the elevational difference between populations from low and high elevation ranged from $660 \mathrm{~m}$ for $P$. avium to $1,360 \mathrm{~m}$ for A. pseudoplatanus, and the average distance between low and high populations was on average $15 \mathrm{~km}$ (Table 1). For each species and both regions, mature trees occur more or less continuously between the selected low and high populations (see fig. 2 in Vitasse et al. 2012 for further details). For each selected population and species, seeds were collected from five randomly sampled trees which were at least $50 \mathrm{~m}$ apart but within an elevational band of $50 \mathrm{~m}$.
Growth conditions

Seeds were sown in an unheated open-window greenhouse at Witterswil $\left(47^{\circ} 29^{\prime} 35^{\prime \prime} \mathrm{N}, 7^{\circ} 31^{\prime} 14^{\prime \prime} \mathrm{E}\right)$ after a cold treatment in spring 2010 (see Kollas et al. 2012 for further details). Immediately after germination, each seedling was replanted in a square container $(14 \mathrm{~cm}$ wide $\times 23 \mathrm{~cm}$ deep) containing three litres of the following substrate: $30 \%$ pumice stone, $20 \%$ bark compost, $20 \%$ quartz sand, $16 \%$ cocofiber, $10 \%$ turf and $4 \%$ clay. A fertilizer was applied in each pot in a slow release tablet form (Plantacote ${ }^{\circledR}$ Pluss $6 \mathrm{M}$ ) containing all essential elements and the full range of trace elements needed for optimal growth $(7.5 \mathrm{~g}$ containing $14 \% \mathrm{~N}, 3.9 \% \mathrm{P}, 11.7 \mathrm{~K}, 1.2 \% \mathrm{Mg}+$ trace elements). The alternative of using similarly reciprocal native soils or inocula was dismissed after mycorrhiza expert consultation. Such a treatment would have exerted uncontrolled bias (site $\times$ provenance $\times$ soil source interactions). About 1 week after repotting, seedlings were moved outside the greenhouse in order to acclimate them to cooler conditions. A total of 4,442 containers were then brought to all common garden sites by trucks during the second week of June 2010 for the eastern region and during the fourth week of June 2010 for the western region.

\section{Common garden sites and experimental design}

Common gardens were established at 437, 1,058, 1,522 and $1,708 \mathrm{~m}$ a.s.l in the western region and at $606,1,002,1,251$ and 1,400 $\mathrm{m}$ a.s.l in the eastern region (Table 2) within the two seed collection areas in the Swiss Alps. The western common gardens were located near St-Maurice, VS $\left(46^{\circ} 12^{\prime} 48^{\prime \prime} \mathrm{N}, 7^{\circ} 00^{\prime} 09^{\prime \prime} \mathrm{E}\right)$ on a south-west facing slope, the eastern gardens were located near Haldenstein, GR $\left(46^{\circ} 52^{\prime} 44^{\prime \prime} \mathrm{N}, 9^{\circ} 31^{\prime} 32^{\prime \prime} \mathrm{E}\right)$ on a south-east facing slope (Table 2). All common gardens were installed in open conditions. Each common garden was divided into three separate blocks, except the highest gardens in each of the

Table 1 Elevation range of the four sampled provenances for the seven species included in the study (West Low, West High, East Low, East High) with the elevational difference $\left(\Delta_{\text {Elevation }}\right)$ and the average distance $\left(\Delta_{\text {Distance }}\right)$ between low and high provenances within each region

\begin{tabular}{|c|c|c|c|c|}
\hline \multirow[t]{2}{*}{ Species } & \multicolumn{2}{|l|}{ West } & \multicolumn{2}{|l|}{ East } \\
\hline & Low-high $\left(\Delta_{\text {Elevation }}\right)(\mathrm{m})$ & $\Delta_{\text {Distance }}(\mathrm{km})$ & Low-high $\left(\Delta_{\text {Elevation }}\right)(\mathrm{m})$ & $\Delta_{\text {Distance }}(\mathrm{km})$ \\
\hline F. excelsior & $420-1,440(1,020)$ & 16.2 & $570-1,230(660)$ & 23.4 \\
\hline P. avium & $356-1,075$ (719) & 27.7 & $575-1,235(660)$ & 12 \\
\hline L. alpinum & $690-1,770(1,080)$ & 1.2 & Species not present & \\
\hline A. pseudoplatanus & $400-1,760(1,360)$ & 16.1 & $590-1,430(840)$ & 9.6 \\
\hline S. aria & $570-1,750(1,180)$ & 7.4 & $620-1,290(670)$ & 14.1 \\
\hline S. aucuparia & $950-2,060(1,110)$ & 15.5 & $930-1,870(930)$ & 27 \\
\hline F. sylvatica & $540-1,240(700)$ & 5.2 & $610-1,280$ (670) & 17.4 \\
\hline
\end{tabular}


two regions that consisted of only two blocks because fewer individuals were available (Online Resource 1). One block consisted of two plots each of $1.50 \mathrm{~m} \times 3 \mathrm{~m}$. Each block contained all species randomly distributed within the block with the four provenances (East Low, East High, West Low, and West High) randomly distributed within species' subplots. Within blocks, each provenance was represented by ten individuals corresponding to five mother trees sampled per population (called hereafter "family") and two replicate seedlings per family. The same systematic design was applied in each of the eight gardens. Thus, a maximum of 30 individual containers per seed provenance were grown in each common garden for all species (five families $\times$ two replicates $\times$ three blocks). Depending on the success of seed germination, some provenances were represented by fewer individuals (see Online Resource 1). Each block was delimited by a wooden frame filled with a $10-\mathrm{cm}$ sand layer separated from the underlying ground by a permeable plastic foil layer. The containers were placed on top of the sand layer with additional sand filling up the gaps between containers in order to insulate the root zones from shortterm atmospheric temperature changes. A shade cloth (40-45\% reduction of incoming solar radiation) was installed in each garden at the beginning of the growing season in spring 2010 and 2011, after leaf emergence for all species in order to reduce evapotranspiration and full sunexposure (seed beds are not commonly under full light in natural forest seedlings). A fence of $2 \mathrm{~m}$ height around the blocks prevented browsing of large herbivores. To avoid water limitation later in the season, plants were watered in all gardens maximally three times a week when the weather was hot and dry, by a local person assigned to each area during the growing season 2010 and 2011. Thus, we aimed to avoid any effects of limiting soil nutrient and water availability on tree phenology in order to focus on the effect of different temperatures induced by the elevational gradient. At the beginning of the second growing season, the slower-growing species $F$. sylvatica and $S$. aria were moved to the southern side of each block to reduce shading effects from the other (taller) species. A few individuals died during the experiment $(<3 \%)$ and a few were damaged by mice $(<1 \%)$. Damaged or poorly growing individuals were not included in the analyses. Thus, an average of 531 individuals per common garden were included in statistical analyses (Online Resource 1). Throughout the paper, the term provenance is used to refer to individuals of a given species coming from seeds sampled at a specific elevation in a specific region (i.e. East Low, East High, West Low, and West High).

\section{Meteorological data}

Air temperature was recorded hourly in each common garden at $0.5 \mathrm{~m}$ above the ground using small data loggers (TidBit v.2 UTBI-001; Onset computer, Bourne, MA, USA) positioned under a white double-layered plastic shelter to prevent any exposure to rain or to direct sunlight. In early spring, data loggers in one common garden (Falera, 1,251 $\mathrm{m}$ a.s.1 in the eastern region) stopped working. In this common garden, early spring temperatures were thus interpolated using linear regression between hourly data of the closest common garden (Arella, 1,002 $\mathrm{m}$ a.s.1, about $20 \mathrm{~km}$ distant) and data recorded in Falera during the period May-June $\left(R^{2}>0.92\right)$. The temperature lapse rate in early spring (March-April) was about $0.49 \mathrm{~K}$ for every $100 \mathrm{~m}$ increase of elevation in the western region and about $0.37 \mathrm{~K}$ in the eastern region (see Table 2). A late spring frost occurred at the highest gardens of both study regions in mid-April 2011 when leaves of the majority of species were unfolded (Online Resource 2). These events caused substantial frost damage only in $F$. excelsior (Online Resource 3).

Table 2 Location, elevation, slope aspect, and temperatures that occurred before leaf flushing began for the eight common gardens

\begin{tabular}{lllllllllll}
\hline Region (close city, exposure) & Site & Elevation $(\mathrm{m})$ & Latitude & Longitude & $T_{1}$ & $T_{2}$ & $T_{3}$ & $T_{4}$ & $T_{5}$ & Spring onset $^{\mathrm{a}}$ \\
\hline West (St-Maurice, SW) & Eslex & 437 & $46^{\circ} 11^{\prime} 52^{\prime \prime} \mathrm{N}$ & $7^{\circ} 01^{\prime} 33^{\prime \prime} \mathrm{E}$ & 2.2 & 3.9 & 8.2 & 14.1 & 16.6 & $14 \mathrm{February}$ \\
& Les Posses & 1,058 & $46^{\circ} 16^{\prime} 26^{\prime \prime} \mathrm{N}$ & $7^{\circ} 02^{\prime} 37^{\prime \prime} \mathrm{E}$ & -0.5 & 2.4 & 5.1 & 11.1 & 13.7 & $5 \mathrm{March}$ \\
& Rosseline & 1,522 & $46^{\circ} 12^{\prime} 55^{\prime \prime} \mathrm{N}$ & $7^{\circ} 02^{\prime} 37^{\prime \prime} \mathrm{E}$ & -2.1 & 1.1 & 2.9 & 8.1 & 10.6 & $24 \mathrm{March}$ \\
& Les Martinaux & 1,708 & $46^{\circ} 12^{\prime} 53^{\prime \prime} \mathrm{N}$ & $7^{\circ} 03^{\prime} 03^{\prime \prime} \mathrm{E}$ & -1.6 & 0.7 & 2.7 & 7.6 & 10.5 & $25 \mathrm{March}$ \\
East (Haldenstein, SE) & Böfel & 606 & $46^{\circ} 52^{\prime} 18^{\prime \prime} \mathrm{N}$ & $9^{\circ} 31^{\prime} 06^{\prime \prime} \mathrm{E}$ & 1.2 & 2.7 & 7.5 & 13.4 & 15.8 & $21 \mathrm{February}$ \\
& Arella & 1,002 & $46^{\circ} 52^{\prime} 25^{\prime \prime} \mathrm{N}$ & $9^{\circ} 30^{\prime} 31^{\prime \prime} \mathrm{E}$ & 0.6 & 2.9 & 6.7 & 12.7 & 14.3 & $25 \mathrm{February}$ \\
& Falera & 1,251 & $46^{\circ} 48^{\prime} 14^{\prime \prime} \mathrm{N}$ & $9^{\circ} 14^{\prime} 23^{\prime \prime} \mathrm{E}$ & -0.5 & 1.8 & 5.6 & 11.7 & 13.6 & $5 \mathrm{March}$ \\
& Nesselboden & 1,400 & $46^{\circ} 52^{\prime} 09^{\prime \prime} \mathrm{N}$ & $9^{\circ} 29^{\prime} 24^{\prime \prime} \mathrm{E}$ & -1.8 & 0.6 & 3.7 & 9.1 & 10.7 & $21 \mathrm{March}$ \\
\hline
\end{tabular}

$T_{1}, T_{2}, T_{3}, T_{4}, T_{5}$, monthly mean temperature $\left({ }^{\circ} \mathrm{C}\right)$ of January, February, March, April and May 2011, respectively

a Spring onset values were derived from linear regressions between monthly mean temperatures from January to May 2011 and time, as the date when the threshold of $5{ }^{\circ} \mathrm{C}$ was reached. These values are used as a proxy for the elevational trends of the advance of spring phenology 


\section{Phenological observations}

The timing of leaf emergence and budset was monitored in all gardens in 2011. In spring 2011, each seedling was observed weekly by one observer assigned to each region to assess the timing of leaf unfolding. These observers were trained at the beginning of the growing season by one of the authors (Y.V.) to minimize observer bias. The stage of the apical bud development was recorded using a categorical scale from 0 (no bud activity) to 4 (leaves out and flat). At stage 1, buds were swollen and/or elongating; at stage 2, buds were open and leaves were partially visible; at stage 3 , leaves had fully emerged from the buds but were still folded, crinkled or pendant, depending on species; at stage 4 , at least one leaf was fully unfolded. Species and provenance were compared using the average date when leaves of seedlings reached stage 3 which was estimated by linear interpolation when necessary (i.e. when this stage occurred in between two monitoring dates). Seedlings that suffered from severe frost damage occurring around the date of bud break were recorded.

Furthermore, we examined each individual to assess the budset, on 20 and 21 July 2011 in the western region and on 26 and 27 July 2011 in the eastern region. The apical bud was regarded as formed (score 1) when it was clearly visible in axils of the uppermost leaves. A score of 0 was attributed to seedlings continuing to produce new leaves or when no winter bud was visible.

\section{Data analysis}

Genetic differentiation in leaf phenology as well as its phenological plasticity to temperature between low and high provenances were tested using general linear model ANOVAs. For the date of leaf unfolding, the statistical model accounted for the following sources of variation: the region of common gardens (west vs. east), the elevation of common gardens nested within the region of common gardens, the region of origin (west vs. east), the elevation of origin nested within the region of origin (low vs. high), the interaction between the region of origin and the elevation of common gardens and the interaction between the elevation of origin and the elevation of common gardens. Although the region of origin could have been considered as random effect by nature, we decided to treat it as fixed effect due to the low number of factor levels (only two regions) which does not allow reliable estimation of the associated variance term when considered as random effect (Bolker et al. 2009). Additionally, the design did not allow the quantification of the seed family effect within provenance because the number of replicates per mother tree was too small and too variable among provenances and gardens to allow for a proper estimation of this effect. Because all the seedlings in each common garden shared the same soil conditions with no limitation in water availability and nutrients, we assumed that a significant main effect of the region or the elevation of common garden on phenology indicates temperature-induced phenotypic plasticity $\left(V_{\mathrm{E}}\right)$. Similarly, a significant interaction between the region or the elevation of origin and the elevation of the garden indicates that the magnitude of the phenological response is dependent on the origin of the population which is the result of genetically based phenotypic plasticity $\left(V_{\mathrm{E}} \times V_{\mathrm{G}}\right)$. Here, it is important to notice that we are considering plasticity at the population level, as an average across individuals from each provenance, rather than in the strict sense, i.e. at the genotype level. The budset score was analyzed for each region of common gardens separately because the monitoring date was different in each region.

The data for spring phenology were examined for assumptions of homogeneity of variance and normal distribution and the binomial data (budset data) were examined for over-dispersion before carrying out the analyses and were found to conform to model requirements. Spring temperature was calculated for each species as the mean temperature from 30-day before the date of leaf unfolding of the earliest provenance to the leaf unfolding date of the latest provenance. Hence, this mean spring temperature differs among species according to their phenology. Linear regressions were used to assess the effect of spring temperature on timing of leaf unfolding for each provenance. These linear regressions represent the reaction norm of the leaf unfolding date of each provenance to temperature changes and allow the comparison of the phenological plasticity among provenances within species and among species. All analyses were performed using R 2.12.2 (R Development Core Team 2011).

\section{Results}

Leaf unfolding date

\section{Phenological plasticity due to temperature $\left(V_{E}\right)$}

In both regions, leaf emergence was significantly delayed with increasing elevation of the common gardens for all species (Fig. 1), with elevation explaining from $41 \%(S$. aucuparia) to $86 \%$ ( $P$. avium) of the total variance in leaf unfolding date (Table 3). Individuals located in the western gardens generally flushed later than those in the eastern gardens (Fig. 1; Table 3; $P$ value highly significant for all species except $F$. sylvatica). The region effect of gardens was principally due to the difference in elevation between the two highest common gardens of the two regions $(290 \mathrm{~m}$ higher in the western region), which resulted in colder 
Fig. 1 Average date of leaf unfolding for each provenance of the seven species examined in the eight common gardens established at different elevations. W-low populations from western part of

Switzerland and low elevation, $W$-high populations from western part of Switzerland and high elevation, E-low

populations from eastern part of Switzerland and low elevation, E-high populations from eastern part of Switzerland and high elevation

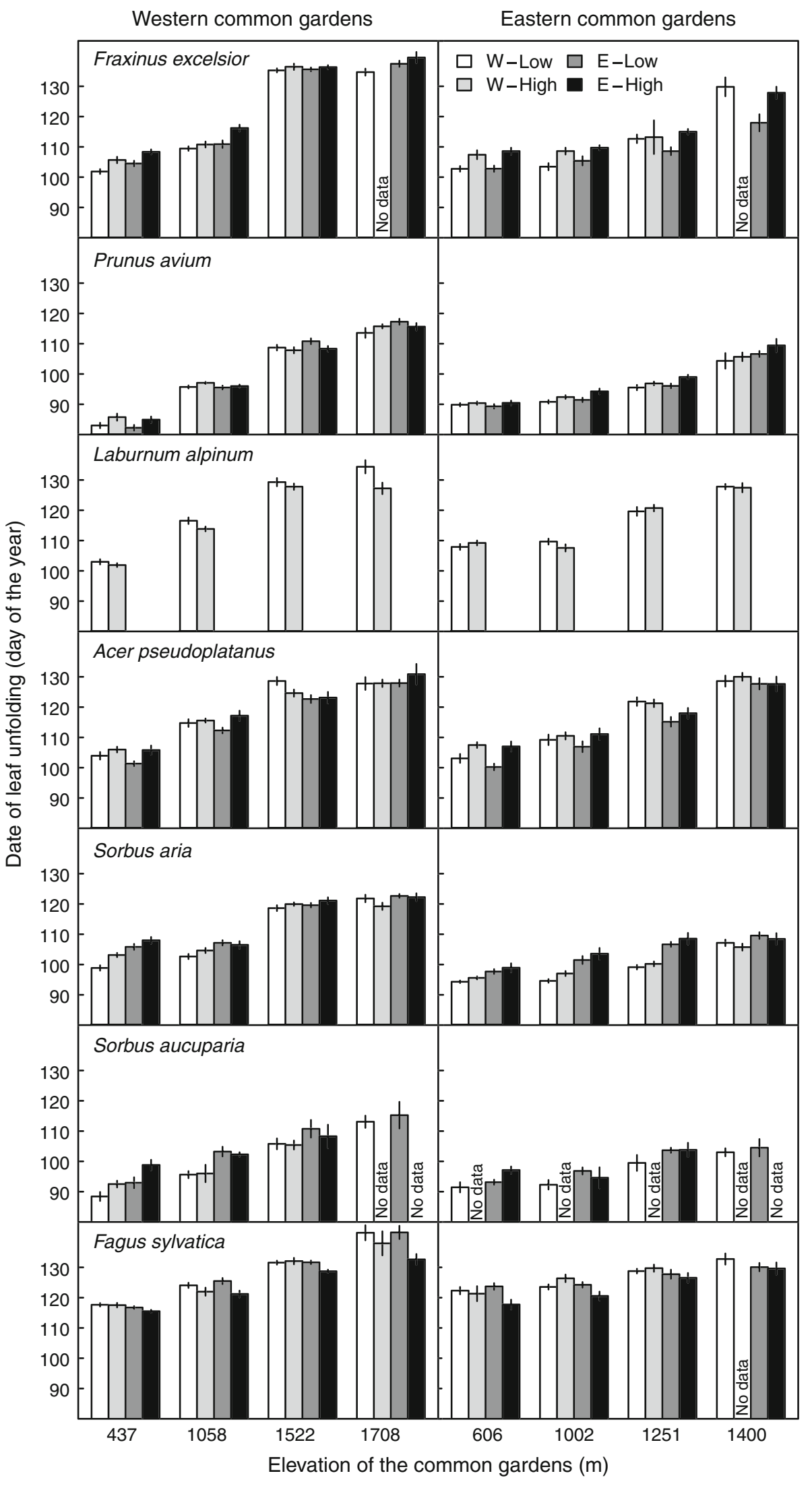




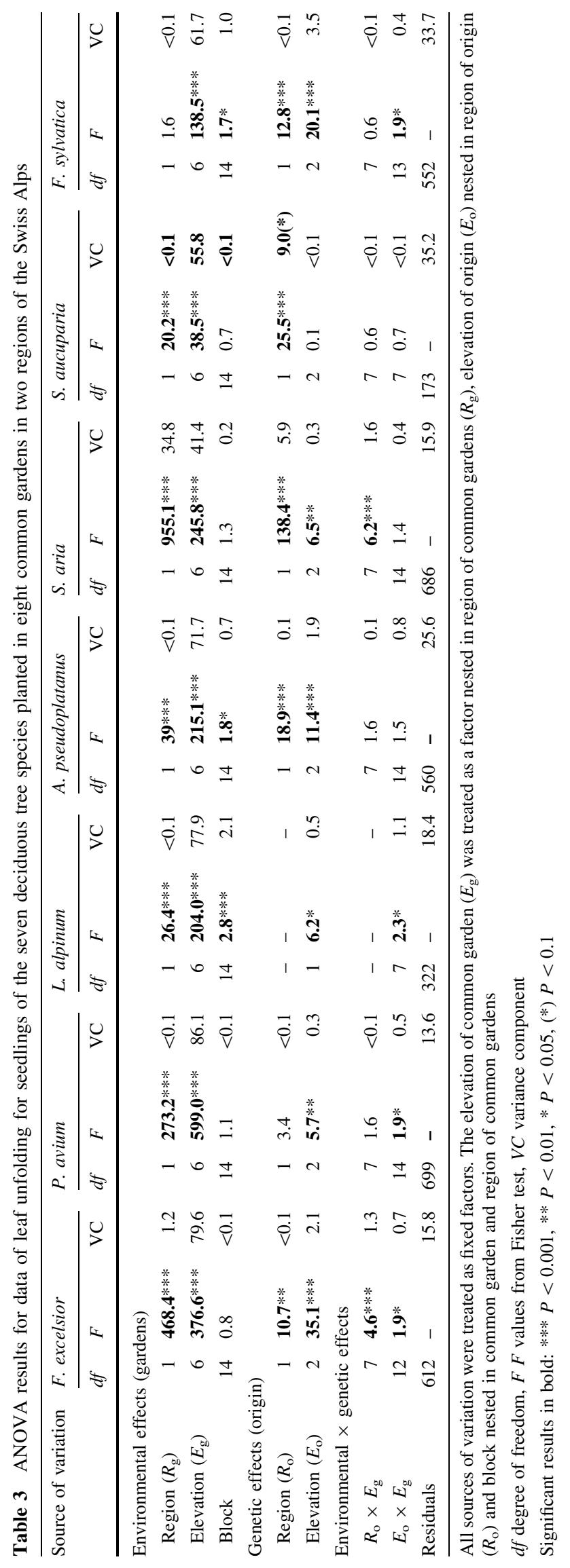



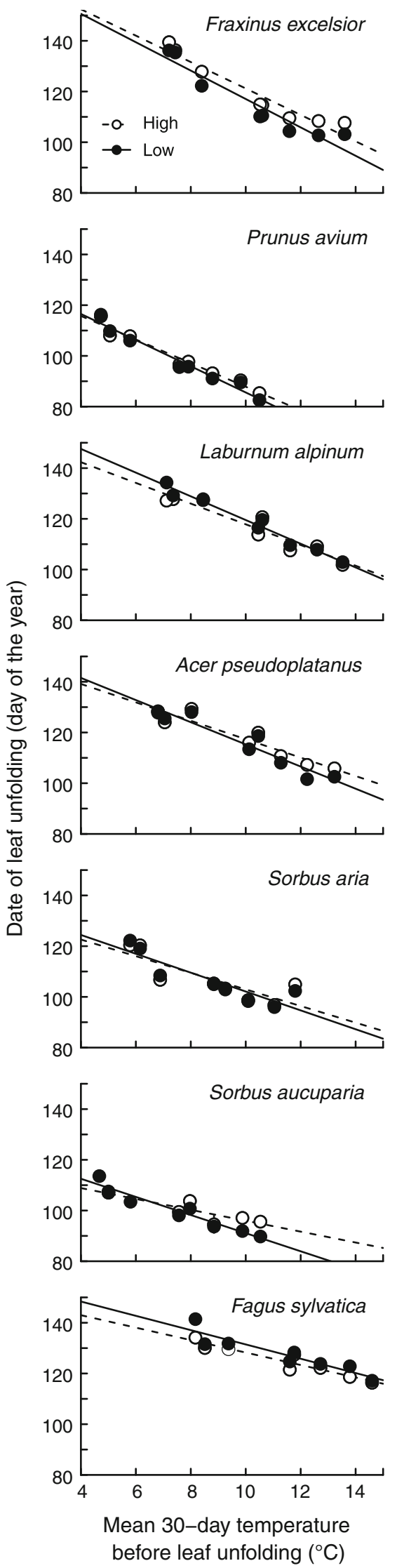

4 Fig. 2 Relationship between mean 30-day air temperature recorded in the common gardens prior to the flushing period and leaf unfolding dates for low and high elevation provenances of the seven studied tree species. The leaf unfolding date corresponds to the mean of all individuals per common garden for low and high elevation provenances (both regions of origin pooled) with standard errors and regression lines. For each species, the temperature corresponds to the mean air temperature during 30 days before the leaf unfolding date of the earliest provenance until the unfolding date of the latest provenance. Black circles and solid lines correspond to populations from low elevations; white circles and dashed lines correspond to populations from high elevations. All linear regressions were significant at the $P<0.05$ level

spring temperatures in the western gardens $(\Delta T=1.6 \mathrm{~K}$, calculated for $T_{2-4}$; see Table 2). The date of leaf unfolding occurred earlier with increasing temperatures (i.e. with decreasing elevation) and was linearly related to temperature across the eight gardens for all species (Fig. 2). However, the magnitude of the phenological plasticity (slopes of regression lines of unfolding date on temperature) differed dramatically among species. For example, $F$. excelsior and $P$. avium exhibited the highest plasticity in response to temperature changes with an average shift of $-5.4 \pm 0.4$ days $\mathrm{K}^{-1} \quad$ (slope value $\pm 1 \quad \mathrm{SD}$ ) and $-4.8 \pm 0.2$ days $\mathrm{K}^{-1}$, whereas $F$. sylvatica showed the lowest plasticity with $-2.6 \pm 0.2$ days $\mathrm{K}^{-1}$ (Table 4 ). The percentage of the total variance observed in leaf unfolding date due to environmental factors (both region and elevation effects) was $86 \%$ for $P$. avium and was more than $50 \%$ for all other species (Fig. 3).

\section{Genetic differentiation among provenances $\left(V_{G}\right)$}

Overall, both the elevation and the region of origin had a significant effect on the timing of leaf unfolding for the majority of tree species, indicating a clear genetic differentiation between low and high provenances as well as between provenances from the western and the eastern part of the Swiss Alps (Table 3). In A. pseudoplatanus, $F$. excelsior, $P$. avium and $S$. aria, populations originating from low elevations flushed significantly earlier than did populations originating from high elevations, especially in the lower common gardens. In addition, eastern provenances flushed slightly later than western provenances (Figs. 1, 2). This region of origin effect was strongest in S. aria, explaining $6.2 \%$ of the total variance (Fig. 1; Table 3). For $F$. sylvatica, both the effect of elevation and region of origin were significant, but the genetic cline of differentiation was opposite to the other species, i.e. high elevation provenances or eastern provenances tended to flush earlier than those from low elevations or from the western region. In contrast, no genetic differentiation was found between low and high provenances for S. aucuparia and between eastern and western region of origin for 
$P$. avium (Table 3). The percentage of variance explained by genetic effects was smaller than the percentage of variance explained by environmental effects, accounting from 0.3 to $9 \%$ for $P$. avium and S. aucuparia, respectively. Interestingly, both Sorbus species exhibited strong phenological differentiation among provenances that accounted for more than $6 \%$ of the total variance (Fig. 3).

\section{Genetic differences in phenological plasticity $\left(V_{G} \times V_{E}\right)$}

A significant interaction in leaf unfolding date between the region of origin and the elevation of the gardens was only found for F. excelsior and S. aria (Table 3). For these two species, provenances from western Alps tended to have a greater plasticity to temperature than provenances from the eastern Alps (Fig. 1). A significant interaction in leaf

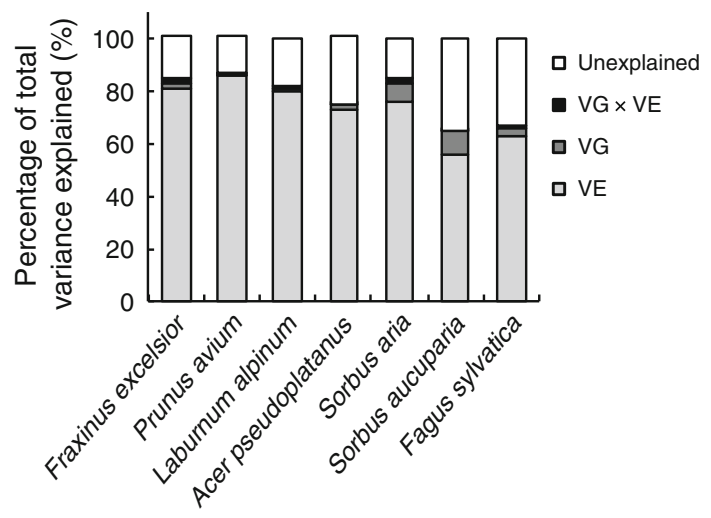

Fig. 3 Contribution (expressed in percentage) of each genetic and environmental component explaining the variability of the leaf unfolding date observed across the common gardens. $V_{\mathrm{E}}$, proportion of the variance due to environmental factors; $V_{\mathrm{G}}$, proportion of the variance due to genetic effects; $V_{\mathrm{E}} \times V_{\mathrm{G}}$, proportion of the variance due to the interaction between genetic and environmental effects. The proportions were directly extracted from the variance component analysis reported in Table 3 unfolding date between the elevation of provenances and the elevation of the gardens was found for four out of seven species, namely $F$. sylvatica, $F$. excelsior, L. alpinum and P. avium (Table 3).

Within region of origin, populations from low elevations exhibited systematically greater plasticity of leaf unfolding date in response to temperature changes than populations from high elevations (Table 4; Fig. 2). On average, the slope of the linear regressions between the leaf unfolding date and spring temperature was $0.59 \pm 0.10$ days $\mathrm{K}^{-1}$ greater for low provenances than for high provenances (paired $t$ test: $t=-5.73, P<0.001$ ). However, within species, no significant difference was found among provenances in their phenological shift to changing temperatures (tested by analysis of covariance: $P>0.05$ ). The variance component due to interactions between environment (region or elevation of the gardens) and provenances (region or elevation of origin) was much smaller than $V_{\mathrm{E}}$ and $V_{\mathrm{G}}$, reaching a maximum of only $2 \%$ for $S$. aria and F. excelsior (Fig. 3).

\section{Budset timing}

\section{Plasticity due to environment $\left(V_{E}\right)$}

Within a region, elevation of gardens significantly affected bud formation in all species (Table 5; Fig. 4). Budset tended to occur later in gardens located at high elevation, irrespective of the provenance. This was particularly visible in the western gardens, where the two highest gardens were situated above 1,500 $\mathrm{m}$ a.s.1 (Fig. 4).

\section{Genetic differentiation among provenances $\left(V_{G}\right)$}

All species except $L$. alpinum and $F$. excelsior exhibited genetic differentiation in the timing of budset between

Table 4 Response of the date of leaf unfolding to mean 30-day temperature occurring before leaf unfolding for each provenance of the seven examined tree species (slope of the linear regressions, days $\mathrm{K}^{-1} \pm 1 \mathrm{SD}$ )

\begin{tabular}{|c|c|c|c|c|c|}
\hline Provenance & W-Low & W-High & E-Low & E-High & Overall \\
\hline F. excelsior & $-6.0 \pm 0.6$ & $-5.0 \pm 1.0$ & $-5.4 \pm 0.9$ & $-5.1 \pm 0.6$ & $-5.4 \pm 0.4$ \\
\hline P. avium & $-4.7 \pm 0.3$ & $-4.5 \pm 0.4$ & $-5.3 \pm 0.4$ & $-4.7 \pm 0.4$ & $-4.8 \pm 0.2$ \\
\hline L. alpinum & $-4.7 \pm 0.3$ & $-4.1 \pm 0.5$ & - & - & $-4.4 \pm 0.3$ \\
\hline A. pseudoplatanus & $-4.3 \pm 0.6$ & $-3.6 \pm 0.6$ & $-4.4 \pm 0.6$ & $-3.7 \pm 0.5$ & $-4.0 \pm 0.3$ \\
\hline S. aria & $-4.2 \pm 0.8$ & $-3.4 \pm 0.9$ & $-3.3 \pm 0.8$ & $-2.9 \pm 0.9$ & $-3.5 \pm 0.4$ \\
\hline S. aucuparia & $-3.6 \pm 0.5$ & - & $-3.5 \pm 0.4$ & $-2.1 \pm 0.7$ & $-3.0 \pm 0.3$ \\
\hline F. sylvatica & $-2.9 \pm 0.5$ & $-2.6 \pm 0.6$ & $-2.7 \pm 0.5$ & $-2.4 \pm 0.3$ & $-2.6 \pm 0.2$ \\
\hline
\end{tabular}

For each species, temperature corresponds to the mean 30-day temperature before the leaf unfolding date of the earliest provenance to the leaf unfolding date of the latest provenance

W-Low provenance from western region and low elevation, W-High western region and high elevation, E-Low eastern region and low elevation, E-High eastern region and high elevation

All slopes were significantly different from $0(P<0.05)$ 


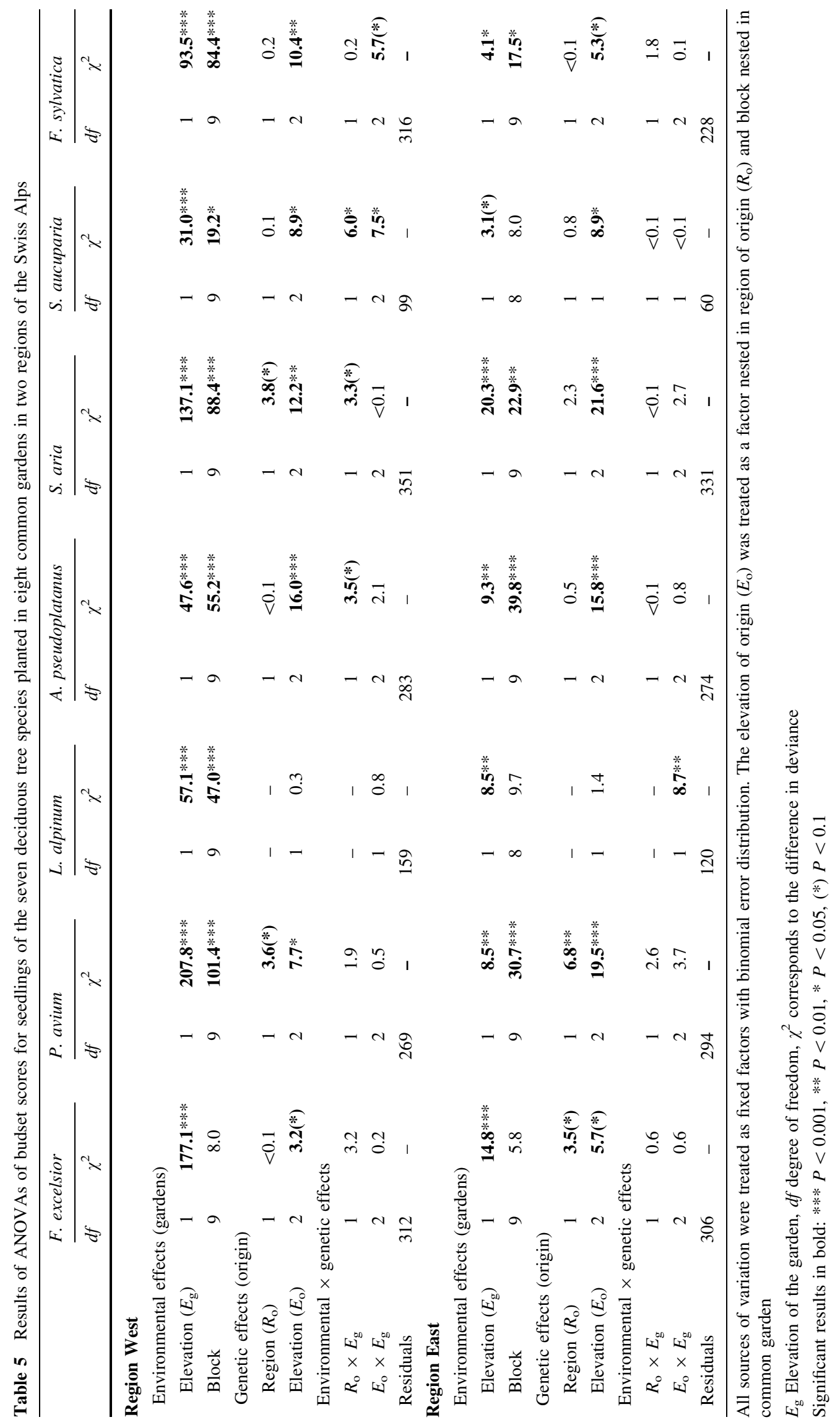


Fig. 4 Percentage of individuals per provenance reaching budset at the end of July 2011 for each of the four provenances studied within each species in the eight common gardens established at different elevations. Symbols as in Fig. 1

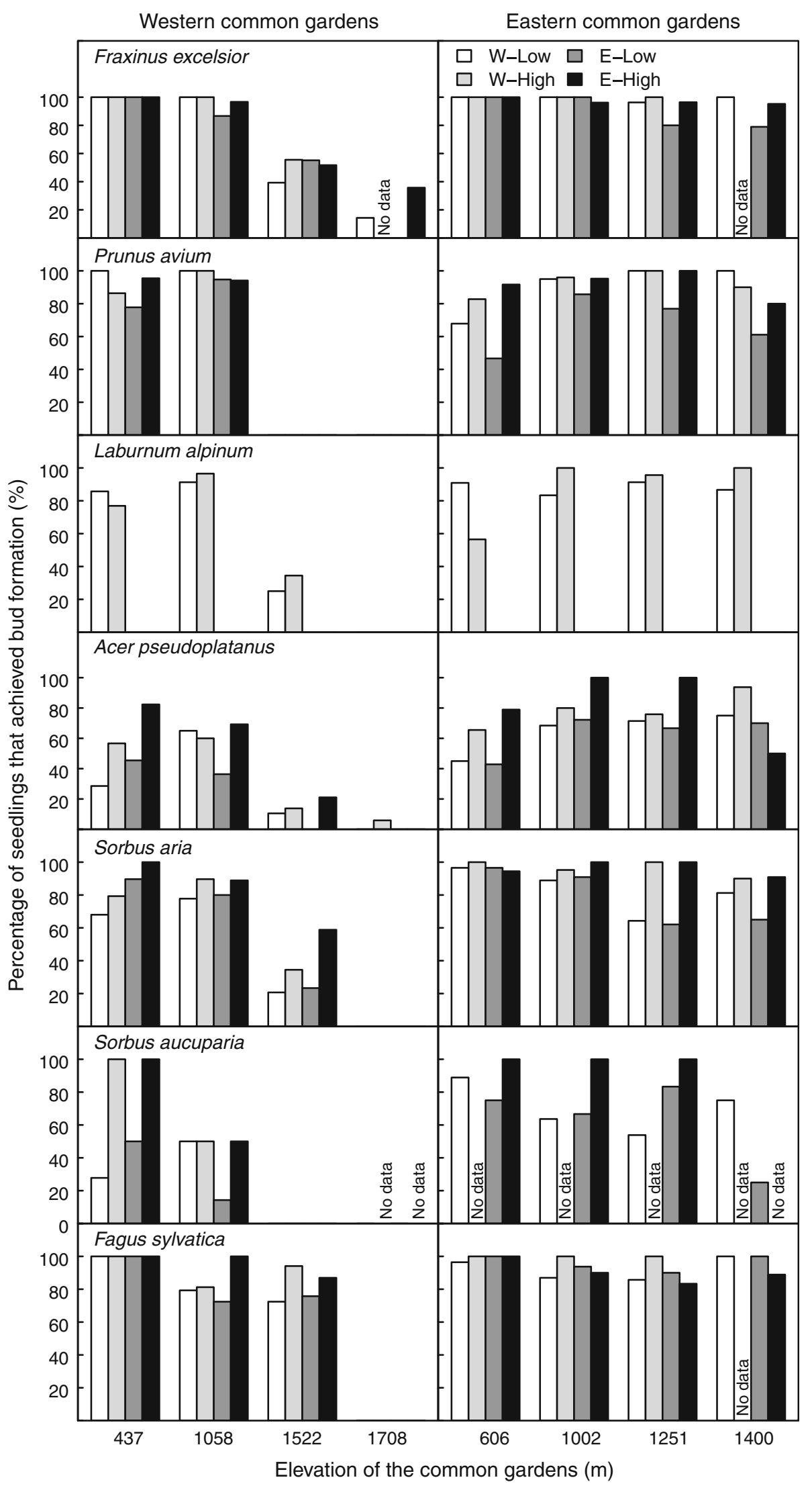


provenances originating from low and high elevations (Table 5). Formation of apical buds tended to occur earlier for provenances originating from high elevations irrespective of the elevation of the garden (Fig. 4). This effect was quite strong for A. pseudoplatanus and both Sorbus species. No significant effect of the region of origin was detected in budset score, except for $P$. avium in the eastern gardens, where populations from the western region of origin tended to set buds earlier than populations from the eastern region of origin.

\section{Genetic differences in phenological plasticity $\left(V_{G} \times V_{E}\right)$}

Only few significant interactions between environmental and genetic effects were detected for budset score (Table 5). Interactions between elevation of origin and elevation of the gardens were detected in budset timing for $S$. aucuparia in the western gardens and for L. alpinum in the eastern gardens. An interaction between the region of origin and the elevation of the gardens was also detected in $S$. aucuparia in the western gardens. For all other species no significant interaction was found between environmental and genetic effects.

\section{Discussion}

The common gardens used in this study enabled the partitioning of environmental and genetic components responsible for tree seedling phenological patterns observed in situ. Furthermore, the experimental set-up allowed us to test exclusively the effect of temperature on tree seedling phenology as seedlings shared the same growth history and soil, and because they grew without water limitations and under standardized nutrient supply throughout the test period. Overall, our results showed that tree seedlings exhibited a strong phenological plasticity in their leaf unfolding date in response to temperature with substantial variation among species. Further, we demonstrated that the high elevation provenances exhibited smaller phenological plasticity, irrespective of the species and that phenological patterns along elevational gradients are, to a large extent, controlled by environmental conditions and to a much lesser extent by genetic differentiation among populations and interactions between these two drivers.

Plasticity of the leaf unfolding date $\left(V_{\mathrm{E}}\right.$ and $\left.V_{\mathrm{E}} \times V_{\mathrm{G}}\right)$

This study highlighted high inter-specific variations in the degree of phenological plasticity to changing temperatures, and that climate (in essence temperature) is the main driver of phenological plasticity in tree seedlings in spring. The shifts of leaf unfolding date with elevation or spring temperature found here were close to the ones found in situ on mature trees along temporal or spatial gradients in other mountain areas (Lebourgeois et al. 2010; Davi et al. 2011; Cufar et al. 2012). For example, Vitasse et al. (2009b) reported along elevational gradients in Pyrenees (France) a comparable shift of 1.9 days $\mathrm{K}^{-1}$ for $F$. sylvatica, 5.0 days $\mathrm{K}^{-1}$ for $A$. pseudoplatanus, and 6.6 days $\mathrm{K}^{-1}$ for $F$. excelsior with a similar ranking among these species. Hence, our results suggest that, under continued global warming, tree species having high phenological plasticity in response to temperature (e.g., $F$. excelsior or A. pseudoplatanus) will likely respond to a greater extent than species with low phenological plasticity (e.g., $F$. sylvatica or $S$. aucuparia). Different responses of phenology to temperature change among species could ultimately affect their competitive abilities and elevational distributions. Species exhibiting the highest phenological plasticity might be temperature-dependent only and at risk of frost damage, while species with low plasticity might have a dual control of bud burst by temperature and photoperiod and be less at risk to track unusual weather. The role of the photoperiod in modulating bud burst dates has been previously demonstrated in $F$. sylvatica growing under controlled conditions (Wareing 1953; Heide 1993; Caffarra and Donnelly 2011; Basler and Körner 2012). Accordingly, F. sylvatica exhibited the lowest phenological plasticity to temperature in this study, which might reflect a photoperiodically controlled delay of bud burst at the lowest elevation gardens. Interestingly, and in line with our hypothesis, the genetic differentiation between low and high provenances affects the magnitude of the plasticity, given that for all species low elevation provenances exhibited greater phenological plasticity than high elevation provenances to temperature changes induced by elevational gradients used for the experimental gardens. This pattern might have been induced either by a directional selection for reduced temperature sensitivity or a more stringent interaction with photoperiodism, which together may reduce the risk of damage by unpredictable late spring frost events after warm weather episodes. This interaction between provenance and environment has crucial implication for modeling future phenological responses of temperate tree species. Variation in responses to temperature among populations might reduce the predictive power and the transferability of phenological models when they are calibrated on genetically differentiated populations. Nevertheless, we found that the environmental component of the plasticity was far stronger than genetic effects, highlighting that phenotypic variations of leaf phenology observed in situ for tree seedlings are mainly the consequence of plasticity due to environmental variation rather than genetic effects. This is in line with the few studies that 
have adequately separated and quantified genetic and environmental contributions on leaf traits related to tree fitness (Kramer 1995; Baliuckas and Pliura 2003; Vitasse et al. 2010; Bresson et al. 2011). However, genetic differentiation among tree populations might be expected to be more pronounced along latitudinal gradients than along elevational gradients, because of the greater distance between core and leading edge populations that could mitigate gene flow. Directional selection may therefore more easily lead to genetic differentiation along latitudinal gradients (Jump et al. 2009), which, on the other hand, would reduce the genetic potential of populations growing on their upper latitudinal to respond to ongoing climate warming.

Genetic differentiation in the leaf unfolding date between low and high provenances

Genetic differentiation among populations of tree seedlings can be due to differences in chilling and forcing requirement to break bud dormancy, or in their different sensitivity to photoperiod. For the majority of the species, our results showed that provenances from high elevations tended to flush later than provenances from low elevations, similarly to the phenotypic cline observed in situ along elevational gradients (co-gradient variation). Although a genetic differentiation of the date of leaf unfolding was often found among provenances from different elevations in common garden experiments, the genetic cline can be opposite to the phenotypic cline observed along environmental gradients (counter-gradient variation). For example, seedling populations from high elevations were found to flush/sprout earlier than those from lower elevations in Abies amabilis, Abies lasiocarpa, Pseudotsuga menziesii and F. sylvatica (Worrall 1983; vonWuehlisch et al. 1995; Chmura and Rozkowski 2002; Acevedo-Rodriguez et al. 2006; Vitasse et al. 2009a; Gomory and Paule 2011), whereas they exhibited delayed flushing in Prunus serotina, F. excelsior and Quercus petraea (Barnett and Farmer 1980; Vitasse et al. 2009a; Alberto et al. 2011), or no significant difference in an array of species (Sharik and Barnes 1976; Vitasse et al. 2009a). These contrasting results demonstrate that species react differently but consistently to the evolutionary forces occurring along elevational gradients. The genetic clines occurring along environmental gradients have been generally thought as a consequence of divergent selection among populations due to either biotic or abiotic selection pressures. However, a recent study suggested that interaction between gene flow and assortative mating occurring along strong environmental gradients may lead to such co-variation of genetic and phenotypic clines among populations, without any divergent selection (Soularue and Kremer 2012). Nevertheless, divergent selection may have shaped both co-gradient and counter-gradient variation among species co-existing along a same environmental gradient, depending on their sensitivity to a given selective pressure. In particular, along elevational gradients the balance between maximizing growth and minimizing the risk of frost damage might be a crucial evolutionary force leading to genetic differentiation in phenology between populations from low and high elevations. The short duration of the growing season at high elevations can be critical for the development of mature seeds and hardened tissues and buds for winter. Early flushing, thus, lengthens the period for growth, and subsequently increases competitive ability and the chance of producing mature seeds, while it simultaneously increases the risk of being exposed to late frosts that could damage flowers, leaves and meristem tissues. Thus, at the elevational limit of a species' range, two contrasting "strategies" might be selected for, possibly resulting in different clines among species co-existing along the same climatic gradient. In line with other studies, we found that genetic and phenotypic clines vary in opposite directions for seedlings of $F$. sylvatica, that is, seedlings from high elevations flushed earlier than those from low elevations when planted in a common garden (vonWuehlisch et al. 1995; Chmura and Rozkowski 2002; Vitasse et al. 2009a, 2010; Gomory and Paule 2011). Natural selection may have favored individuals exhibiting earlier leaf unfolding at high elevation, suggesting that for this species developmental constraints restrict fitness more than the risk of frost damage does. However, because it has been shown that significant genetic variation within populations can be preserved in traits under strong selective pressure (Howe et al. 2003), further investigations are needed to assess the genetic variation of phenological traits existing within populations along elevational gradients.

Environmental control of budset timing and genetic differentiation between low and high elevation provenances

Maturation of winter buds in late summer and rising frost hardiness in autumn must be initiated before occurrence of frosts and are therefore assumed to play a key role in tree fitness (Hurme et al. 1997; Charrier and Ameglio 2011). Until recently, photoperiod (detected by the phytochrome receptor) was thought to be the only environmental control that determines budset timing of the majority of temperate tree species (Tanino et al. 2010). Yet, recent experimental studies demonstrated that, under the same photoperiod, temperature has a modulating role on the endogenous program of summer/autumn phenology, with low temperatures advancing the onset of growth cessation in several deciduous tree species (Molmann et al. 2005; Tanino et al. 2010; Heide 2011; Rohde et al. 2011). Although the date of 
monitoring budset in this study was too late to unambiguously detect and disentangle both environmental and genetic effects, we found that, within the region of the gardens, the elevation of the gardens significantly affected bud formation in all species. Further, bud formation occurred later in the two highest elevation gardens, irrespective of provenances.

Except for $L$. alpinum and $F$. excelsior, a genetic differentiation between low and high elevation provenances was found, with low elevation provenances tending to achieve budset later than high elevation provenances. Among the few common garden experiments which investigated the time of growth cessation or budset with respect to the elevation of provenances, the same trend was reported for F. sylvatica (Chmura and Rozkowski 2002) and for two Betula species (Sharik and Barnes 1976). Genetic differentiation between low and high elevation provenances is likely the result of directional selection favoring individuals having earlier budset and leaf senescence at high elevation, and, thus, higher freezing tolerance in early autumn (Charrier and Ameglio 2011).

\section{Conclusions}

The ability of populations to thrive under contrasting climates depends on their genetic differentiation across climatic gradients and the genetic variation within populations (Aitken et al. 2008; Wang et al. 2010). In agreement with our first hypothesis, this study demonstrated that seedlings from tree populations growing at their upper elevational limits exhibit genetic adaptation in leaf phenology. Directional selection seems to operate in spite of the short distance among populations along elevational gradients and a presumably abundant gene flow across such gradients (Alberto et al. 2010). Our results also underlined that seedlings of tree populations in the Alps have high phenological plasticity in response to temperature changes, with substantial inter-specific differences. Interestingly, seedlings from high elevation provenances exhibited a lower phenological plasticity to temperature than those from low elevation provenances. Due to the large environmental effect and the small genetic effect on leaf unfolding date, our results suggest that both seedlings of populations of deciduous tree species growing at the upper elevation margin and of lower elevation populations have a high phenological plasticity to track ongoing climate change. Seedlings are known to exhibit more opportunistic phenology than adult trees, given that their success is not only constrained by a short thermal season but also by canopy closure, and thus light limitation (Augspurger 2008). Hence, the dominance of phenotypic over genotypic responses (in the sense of tracking concurrent temperatures) might be seedling-specific. We thus expect genotypic responses to be more pronounced in the adult life stage.

Acknowledgments We are grateful to Serge Ricciardelli and Roger Frei for their assistance in the field for monitoring spring phenology. We wish to thank Fernando Koostella, Snorri Örn Rafnsson, Lea Steinle, Pascale Flury, Martin Trischler and José Monteiro for their help in the construction and maintenance of the common gardens. We are also grateful to the Swiss Army for logistic help to move the containers to all common gardens, as well as the municipality of Bex, Lavey-Morcles and Haldenstein and the local foresters for their great support. The research leading to these results has been funded by the European Research Council (ERC) grant 233399 (project TREELIM). We are grateful to two anonymous reviewers for their valuable comments improving a previous version of the manuscript.

\section{References}

Acevedo-Rodriguez R, Vargas-Hernandez JJ, Lopez-Upton J, Mendoza JV (2006) Effect of geographic origin and nutrition on shoot phenology of Mexican Douglas-fir (Pseudotsuga sp.) seedlings. Agrociencia 40:125-137

Aitken SN, Yeaman S, Holliday JA, Wang T, Curtis-McLane S (2008) Adaptation, migration or extirpation: climate change outcomes for tree populations. Evol Appl 1:95-111. doi:10.1111/J.1752-4571. 2007.00013.X

Alberto F, Niort J, Derory J, Lepais O, Vitalis R, Galop D, Kremer A (2010) Population differentiation of sessile oak at the altitudinal front of migration in the French Pyrenees. Mol Ecol 19:2626-2639. doi:10.1111/j.1365-294X.2010.04631.x

Alberto F, Bouffier L, Louvet JM, Lamy JB, Delzon S, Kremer A (2011) Adaptive responses for seed and leaf phenology in natural populations of sessile oak along an altitudinal gradient. J Evol Biol 24:1442-1454. doi:10.1111/j.1420-9101.2011.02277.x

Augspurger CK (2008) Early spring leaf out enhances growth and survival of saplings in a temperate deciduous forest. Oecologia 156:281-286. doi:10.1007/s00442-008-1000-7

Baliuckas V, Pliura A (2003) Genetic variation and phenotypic plasticity of Quercus robur populations and open-pollinated families in Lithuania. Scand J For Res 18:305-319. doi:10.1080/ 02827580310005153

Baliuckas V, Lagerstrom T, Norell L, Erksson G (2005) Genetic variation among and within populations in Swedish species of Sorbus aucuparia L. and Prunus padus L. assessed in a nursery trial. Silvae Genet 54:1-8

Barnett PE, Farmer RE Jr (1980) Altitudinal variation in juvenile characteristics of southern Appalachian black cherry (Prunus serotina Ehrh.). Silvae Genet 29:157-160

Basler D, Körner C (2012) Photoperiod sensitivity of bud burst in 14 temperate forest tree species. Agric For Meteorol. doi: 10.1016/j.agrformet.2012.06.001

Billington HL, Pelham J (1991) Genetic-variation in the date of budburst in scottish birch populations-implications for climate change. Funct Ecol 5:403-409

Bolker BM, Brooks ME, Clark CJ, Geange SW, Poulsen JR, Stevens MHH, White J-SS (2009) Generalized linear mixed models: a practical guide for ecology and evolution. Trends Ecol Evol 24:127-135. doi:10.1016/j.tree.2008.10.008

Bresson CC, Vitasse Y, Kremer A, Delzon S (2011) To what extent is altitudinal variation of functional traits driven by genetic adaptation in European oak and beech? Tree Physiol 31:1164-1174. doi: 10.1093/treephys/tpr084 
Broadhead JS, Ong CK, Black CR (2003) Tree phenology and water availability in semi-arid agroforestry systems. For Ecol Manag 180:61-73. doi:10.1016/S0378-1127(02)00602-3

Caffarra A, Donnelly A (2011) The ecological significance of phenology in four different tree species: effects of light and temperature on bud burst. Int J Biometeorol 55:711-721. doi: 10.1007/s00484-010-0386-1

Charrier G, Ameglio T (2011) The timing of leaf fall affects cold acclimation by interactions with air temperature through water and carbohydrate contents. Environ Exp Bot 72:351-357. doi: 10.1016/j.envexpbot.2010.12.019

Chmura DJ, Rozkowski R (2002) Variability of beech provenances in spring and autumn phenology. Silvae Genet 51:123-127

Chuine I (2010) Why does phenology drive species distribution? Philos Trans R Soc Lond B 365:3149-3160. doi:10.1098/ rstb.2010.0142

Cufar K, De Luis M, Saz MA, Crepinsek Z, Kajfez-Bogataj L (2012) Temporal shifts in leaf phenology of beech (Fagus sylvatica) depend on elevation. Trees Struct Funct. doi:10.1007/s00468012-0686-7

Davi H, Gillmann T, Cailleret M, Bontemps A, Fady B, Lefèvre F (2011) Diversity of leaf unfolding dynamics among tree species: new insights from a study along an altitudinal gradient. Agric For Meteorol 151:1504-1513. doi:10.1016/J.Agrformet.2011. 06.008

Doi H, Takahashi M, Katano I (2010) Genetic diversity increases regional variation in phenological dates in response to climate change. Glob Change Biol 16:373-379. doi:10.1111/j.1365-2486. 2009.01993.x

Gomory D, Paule L (2011) Trade-off between height growth and spring flushing in common beech (Fagus sylvatica L.). Ann For Sci 68:975-984. doi:10.1007/s13595-011-0103-1

Heide OM (1993) Dormancy release in beech Buds (Fagus sylvatica) requires both chilling and long days. Physiol Plant 89:187-191

Heide OM (2011) Temperature rather than photoperiod controls growth cessation and dormancy in Sorbus species. J Exp Bot. doi:10.1093/jxb/err213

Hoffmann AA, Sgro CM (2011) Climate change and evolutionary adaptation. Nature 470:479-485. doi:10.1038/nature09670

Howe GT, Saruul P, Davis J, Chen THH (2000) Quantitative genetics of bud phenology, frost damage, and winter survival in an F-2 family of hybrid poplars. Theor Appl Genet 101:632-642

Howe GT, Aitken SN, Neale DB, Jermstad KD, Wheeler NC, Chen THH (2003) From genotype to phenotype: unraveling the complexities of cold adaptation in forest trees. Can J Bot 81:1247-1266. doi:10.1139/B03-141

Hurme P, Repo T, Savolainen O, Paakkonen T (1997) Climatic adaptation of bud set and frost hardiness in Scots pine (Pinus sylvestris). Can J For Res 27:716-723

Jump AS, Matyas C, Penuelas J (2009) The altitude-for-latitude disparity in the range retractions of woody species. Trends Ecol Evol 24:694-701. doi:10.1016/j.tree.2009.06.007

Kollas C, Vitasse Y, Randin CF, Hoch G, Korner C (2012) Unrestricted quality of seeds in European broad-leaved tree species growing at the cold boundary of their distribution. Ann Bot 109:473-480. doi:10.1093/aob/mcr299

Körner C (2000) Why are there global gradients in species richness? Mountains might hold the answer. Trends Ecol Evol 15:513-514. doi:10.1016/s0169-5347(00)02004-8

Kramer K (1995) Phenotypic plasticity of the phenology of seven European tree species in relation to climatic warming. Plant Cell Environ 18:93-104

Kremer A, Ronce O, Robledo-Arnuncio JJ, Guillaume F, Bohrer G, Nathan R, Bridle JR, Gomulkiewicz R, Klein EK, Ritland K, Kuparinen A, Gerber S, Schueler S (2012) Long-distance gene flow and adaptation of forest trees to rapid climate change. Ecol Lett 15:378-392. doi:10.1111/j.1461-0248.2012.01746.x

Langlet O (1971) Two hundred years gynaecology. Taxon 20:653722

Lebourgeois F, Pierrat JC, Perez V, Piedallu C, Cecchini S, Ulrich E (2010) Simulating phenological shifts in French temperate forests under two climatic change scenarios and four driving global circulation models. Int J Biometeorol 54:563-581. doi: 10.1007/s00484-010-0305-5

Lindner M, Maroschek M, Netherer S, Kremer A, Barbati A, GarciaGonzalo J, Seidl R, Delzon S, Corona P, Kolstrom M, Lexer MJ, Marchetti M (2010) Climate change impacts, adaptive capacity, and vulnerability of European forest ecosystems. For Ecol Manag 259:698-709. doi:10.1016/j.foreco.2009.09.023

Molmann JA, Asante DKA, Jensen JB, Krane MN, Ernstsen A, Junttila O, Olsen JE (2005) Low night temperature and inhibition of gibberellin biosynthesis override phytochrome action and induce bud set and cold acclimation, but not dormancy in PHYA overexpressors and wild-type of hybrid aspen. Plant Cell Environ 28:1579-1588. doi:10.1111/j.1365-3040.2005.01395.x

Morgenstern EK (1996) Geographic variation in forest trees: genetic basis and application of knowledge in silviculture. University of British Columbia Press, Vancouver

Oleksyn J, Modrzynski J, Tjoelker MG, Zytkowiak R, Reich PB, Karolewski P (1998) Growth and physiology of Picea abies populations from elevational transects: common garden evidence for altitudinal ecotypes and cold adaptation. Funct Ecol 12:573-590

Pigliucci M, Murren CJ, Schlichting CD (2006) Phenotypic plasticity and evolution by genetic assimilation. J Exp Biol 209:2362-2367. doi:10.1242/jeb.02070

Polgar CA, Primack RB (2011) Leaf-out phenology of temperate woody plants: from trees to ecosystems. New Phytol 191:926-941. doi: 10.1111/j.1469-8137.2011.03803.x

Premoli AC, Raffaele E, Mathiasen P (2007) Morphological and phenological differences in Nothofagus pumilio from contrasting elevations: evidence from a common garden. Austral Ecol 32:515-523. doi:10.1111/j.1442-9993.2007.01720.x

R Development Core Team (2011) R: a language and environment for statistical computing. R Foundation for Statistical Computing, Vienna, Austria

Rehfeldt GE, Tchebakova NM, Parfenova YI, Wykoff WR, Kuzmina NA, Milyutin LI (2002) Intraspecific responses to climate in Pinus sylvestris. Glob Change Biol 8:912-929

Rohde A, Bastien C, Boerjan W (2011) Temperature signals contribute to the timing of photoperiodic growth cessation and bud set in poplar. Tree Physiol 31:472-482. doi:10.1093/treephys/tpr038

Savolainen O, Pyhajarvi T, Knurr T (2007) Gene flow and local adaptation in trees. Annu Rev Ecol Evol Syst 38:595-619. doi: 10.1146/annurev.ecolsys.38.091206.095646

Schlichting CD (1986) The evolution of phenotypic plasticity in plants. Annu Rev Ecol Syst 17:667-693. doi:10.1146/annurev.ecolsys. 17.1.667

Schlichting CD, Pigliucci M (1993) Control of phenotypic plasticity via regulatory genes. Am Nat 142:366-370

Sharik TL, Barnes BV (1976) Phenology of shoot growth among diverse populations of yellow birch (Betula alleghaniensis) and sweet birch (B. lenta). Can J Bot 54:2122-2129

Soularue J-P, Kremer A (2012) Assortative mating and gene flow generate clinal phenological variation in trees. BMC Evol Biol 12:79. doi:10.1186/1471-2148-12-79

Tanino KK, Kalcsits L, Silim S, Kendall E, Gray GR (2010) Temperature-driven plasticity in growth cessation and dormancy development in deciduous woody plants: a working hypothesis suggesting how molecular and cellular function is affected by 
temperature during dormancy induction. Plant Mol Biol 73:49-65. doi:10.1007/s11103-010-9610-y

Thompson JD (1991) Phenotypic plasticity as a component of evolutionary change. Trends Ecol Evol 6:246-249. doi: 10.1016/0169-5347(91)90070-e

Tikkanen OP, Julkunen-Tiitto R (2003) Phenological variation as protection against defoliating insects: the case of Quercus robur and Operophtera brumata. Oecologia 136:244-251. doi: 10.1007/S00442-003-1267-7

van Asch M, Visser ME (2007) Phenology of forest caterpillars and their host trees: the importance of synchrony. Annu Rev Entomol 52:37-55. doi:10.1146/annurev.ento.52.110405.091418

Vitasse Y, Delzon S, Bresson CC, Michalet R, Kremer A (2009a) Altitudinal differentiation in growth and phenology among populations of temperate-zone tree species growing in a common garden. Can J For Res 39:1259-1269. doi:10.1139/X09-054

Vitasse Y, Delzon S, Dufrene E, Pontailler JY, Louvet JM, Kremer A, Michalet R (2009b) Leaf phenology sensitivity to temperature in European trees: do within-species populations exhibit similar responses? Agric For Meteorol 149:735-744. doi:10.1016/j. agrformet.2008.10.019

Vitasse Y, Bresson CC, Kremer A, Michalet R, Delzon S (2010) Quantifying phenological plasticity to temperature in two temperate tree species. Funct Ecol 24:1211-1218. doi:10.1111/j. $1365-2435.2010 .01748 . x$
Vitasse Y, Hoch G, Randin CF, Lenz A, Kollas C, Körner C (2012) Tree recruitment of European tree species at their current upper elevational limits in the Swiss Alps. J Biogeogr. doi: 10.1111/j.1365-2699.2012.02697.x

vonWuehlisch G, Krusche D, Muhs HJ (1995) Variation in temperature sum requirement for flushing of beech provenances. Silvae Genet 44:343-346

Wang TL, O'Neill GA, Aitken SN (2010) Integrating environmental and genetic effects to predict responses of tree populations to climate. Ecol Appl 20:153-163. doi:10.1890/08-2257.1

Wareing PF (1953) Growth studies in woody species. V. Photoperiodism in dormant buds of Fagus sylvatica. Physiol Plant 6:692-706

Wesolowski T, Rowinski P (2008) Late leaf development in pedunculate oak (Quercus robur): an antiherbivore defence? Scand J For Res 23:386-394. doi:10.1080/02827580802419026

Willi Y, Van Buskirk J, Schmid B, Fischer M (2007) Genetic isolation of fragmented populations is exacerbated by drift and selection. J Evol Biol 20:534-542. doi:10.1111/j.1420-9101.2006.01263.x

Williams JL, Auge H, Maron JL (2008) Different gardens, different results: native and introduced populations exhibit contrasting phenotypes across common gardens. Oecologia 157:239-248. doi:10.1007/s00442-008-1075-1

Worrall J (1983) Temperature-bud-burst relationships in amabilis and subalpine fir provenance tests replicated at different elevations. Silvae Genet 32:203-209 